\title{
LA BIBLIOTECA ROCÍO (1937-1939) O LAS VIRTUDES DE LA NOVELA ROSA DURANTE LA GUERRA CIVIL ESPAÑOLA
}

\author{
Didier CORDEROT \\ Université Blaise Pascal (Clermont-Ferrand)
}

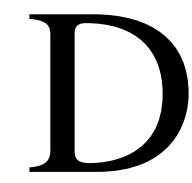
urante mucho tiempo, el problema del difícil acceso a la producción narrativa de la Guerra Civil se zanjaba sacando la conclusión de su casi ausencia. Sin embargo, el empeño de investigadores, universitarios o no ${ }^{1}$, permitió restablecer la verdad: la Guerra Civil acarreó la división del espacio literario pero la narrativa siguió siendo un género cultivado. Si bien las circunstancias no eran idóneas para la novela tradicional - en efecto, se mutiplican los libros que dan cuenta de experiencias vividas adoptando la forma de crónicas de guerra o de testimonios, sobre todo por parte de huidos de la zona republicana ${ }^{2}$ - no faltan sin embargo creaciones, más cortas, por razones obvias, que acatan las pautas de la narrativa. Algunas son ambiciosas como, por ejemplo, Sueños de grandeza, del republicano Antonio Sánchez Barbudo, novela publicada por entregas en la revista Hora de España ${ }^{3}$. Otras lo son menos, por dirigirse a un público no tan elitista pero sí muchísimo más amplio. Es el caso de las novelas rosas ${ }^{4}$, herederas de una larga tradición editorial y comercial -su difusión en los kioscos es determinante- y agrupadas en las llamadas colecciones literarias cuya moda arranca a principios del siglo XX. Sus autores, que en ciertos casos pertenecen a generaciones ya veteranas y por consiguiente ajenas a cualquier vanguardismo literario sospechoso, se encuentran sobre todo en el bando «nacional». Dejando de lado el debate acerca del valor intrínseco de este tipo de literatura, las más veces tildada de «subliteratura» o de «infraliteratura», lo que equivale a entronizar una práctica cultural y menoscabar otra ${ }^{5}$, cabe interrogarse sobre su función en un clima donde impera

\footnotetext{
${ }^{1}$ El mejor ejemplo de la segunda categoría es sin duda Andrés Trapiello que por su erudición abrió importantes posibilidades para la investigación en su libro Las armas y las letras. Literatura y Guerra Civil (1936-1939) (Barcelona, Planeta, 1994).

2 Ignacio Soldevilla Durante habla de «novela testimonial» (cfr. Historia de la novela española (1936-2000), Madrid, Cátedra, 2001, p. 240).

${ }^{3}$ Su versión definitiva, con importantes modificaciones, sólo se publicará en 1946 en Buenos Aires. La editorial Anthropos la volvió a editar en 1994.

${ }^{4}$ El género erótico-pornográfico desaparece por completo.

${ }^{5}$ Eduardo Ruiz Bautista, «En pos del buen lector: censura editorial y clases populares durante el Primer Franquismo (19391945)», en Espacio, Tiempo y Forma, Serie V, Historia Contemporánea, UNED, Facultad de Geografía e Historia, t. 16 , 2004, pp. 231-251.
} 
la violencia. Uno de los casos más singulares entre estas series de novelas publicadas en pleno conflicto es la colección titulada Biblioteca Rocío confeccionada en Sevilla por las Ediciones Betis a partir del mes de abril de 1937 y distribuida exclusivamente, según consta en la cubierta de cada número, por la Editorial Española sita en la burgalesa calle Generalísimo Franco ${ }^{6}$.

\section{Imprimátur $^{7}$}

Las autoridades franquistas consideraban con cierto recelo las novelas populares que según ellas habían contribuido, y seguían haciéndolo en el bando enemigo, a difundir ideas «disolventes». De ahí que decidieran restringir las cantidades de papel atribuidas a las editoriales a partir de abril de 1938. El otro freno a su existencia lo constituyó la censura, a cargo de la Jefatura Nacional de Prensa y Propaganda de Falange Española -a raíz del Decreto de Unificación de los partidos se transformará en Delegación Nacional de FET y de las JONS- y de la Delegación del Estado para Prensa y Propaganda creada en enero de 1937. Fue preciso, pues, para los responsables de la Biblioteca Rocío conseguir el imprimátur censorial. Juan Bautista Viza Caball resolvió el problema al proponer a la Delegación del Estado, en diciembre de 1937, es decir algunos meses después del lanzamiento de la serie, «novelas absolutamente desprovistas del menor interés político y sin ninguna relación con los actuales sucesos» ${ }^{8}$

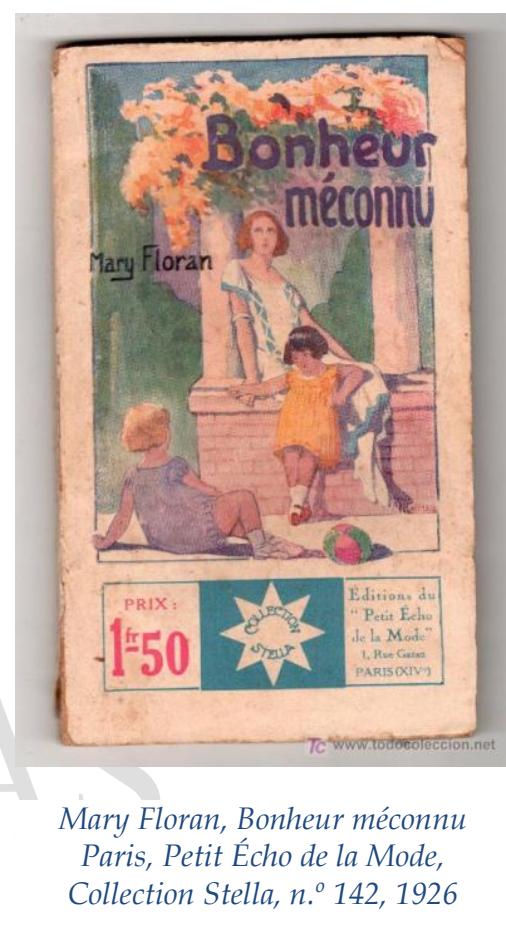
si nos atenemos a las palabras del entonces director de la serie. Al estudiar la lista de los casi doscientos

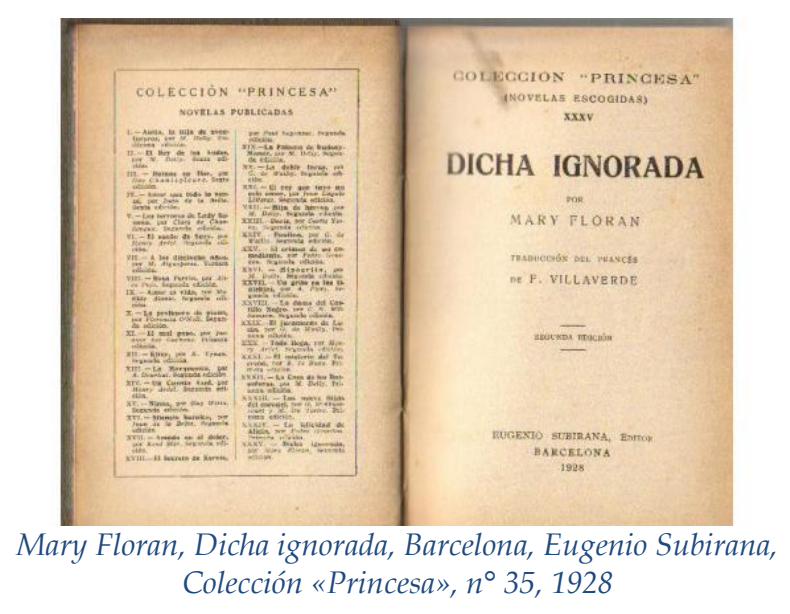

títulos identificados, resulta que la solución para lograr esa inocuidad ideológica consistió en publicar esencialmente textos anteriores a los acontecimientos que procedían en gran medida de la Colección «Princesa» publicada en Barcelona por Eugenio Subirana entre 1923 y 1933. Muchos de ellos fueron refundidos para respetar el tamaño habitual de cada entrega, entre ochenta y cien páginas ${ }^{9}$. Los títulos eran idénticos muchas veces a

\footnotetext{
${ }^{6}$ Dada la falta de fechas precisas de publicación de las novelas de la serie Biblioteca Rocío [BR], sólo podemos emitir hipótesis apoyadas en diferentes fuentes: fecha de redacción indicada a veces al final de los textos, anuncios publicitarios, reseñas publicadas en la prensa, informes de la censura, etc. De ahí la posible repartición siguiente: $\mathrm{n} .^{\circ \mathrm{s}} 1$ a 9: $1937 ; \mathrm{n}$. ${ }^{\circ \mathrm{s}} 10$ a 30: 1938 con una periodicidad bimensual; $n{ }^{\text {os }} 31$ a $54: 1939 ;$ n. $^{\text {os }} 54$ a $78: 1940 ;$ n. $^{\text {os }} 79$ a $102: 1941 ;$ n. $^{\circ} 103$ a 126 : 1942; n. ${ }^{\text {os }} 127$ a 150: $1943 ;$ n. $^{\circ \text { s }} 151$ a $174: 1944 ;$ n. ${ }^{\circ \text { s }} 175$ a 198: 1945.

${ }^{7}$ La mayor parte de las ilustraciones provienen del sitio web www.todocoleccion.net

${ }^{8}$ Archivo General de la Administración (Alcalá de Henares), Cultura, caja 1615.

${ }^{9}$ El texto está impreso a doble columna.
} 


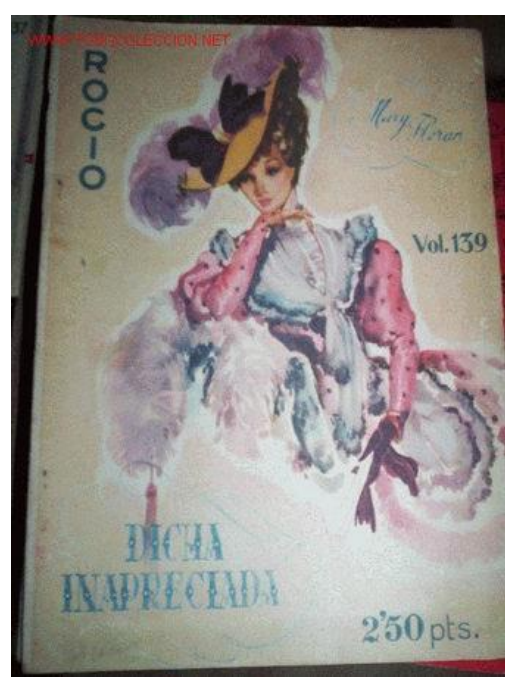

Mary Floran, Dicha inapreciada, Barcelona, BR, n. ${ }^{\circ} 139$

los originales pero podían ser ligeramente modificados o transformados del todo ${ }^{10}$. Al ahondar más el origen de estas novelas se descubre que el vivero de la Colección Princesa fue la muy longeva colección Stella (1919-1953) ${ }^{11}$, colección popular francesa editada por el Petit Écho de la Mode -de ahí la presencia masiva de autores franceses (aproximadamente la mitad del conjunto)- con una línea editorial por lo menos ortodoxa, según la publicidad difundida por sus editores:

La collection «Stella» est la collection idéale des romans pour la famille et les jeunes filles. Son format allongé d'une si jolie élégance a été étudié spécialement pour tenir dans un sac, dans une poche, et dans une petite main. Quand on voit, oublié sur la table, un volume de la collection «Stella», on imagine nécessairement que la main qui l'a posé là est toute menue et toute fine. La collection «Stella» contitue un véritable choix des œuvres les plus remarquables des meilleurs auteurs parmi les romanciers des honnêtes gens. Elle élève et distrait la pensée sans jamais salir l'imagination. La collection «Stella» est une garantie de qualité morale et de qualité littéraire. ${ }^{12}$

Este programa aseguraba al lector un contenido «profiláctico», en un periodo marcado por importantes cambios en la sociedad francesa. Por lo que respecta a las mujeres, consabido es que los llamados Años locos (1919-1929) acarrearon su progresiva emancipación, sobre todo en las clases acomodadas, por la influencia del modelo transgresivo de la garçonne, quien no reparaba en alternar, fumar, practicar deportes, conducir coches, o para mayor inri vivir en unión libre, ostentar su homosexualidad cuando no su bisexualidad. La colección Stella se concibió como una reacción a una moda que propugnaba el acceso de la mujer a la esfera pública. Su carácter aleccionador entroncaba pues perfectamente con la intención anunciada de la Biblioteca Rocío de entretener a un público lector familiar, y ponerle a salvo de ideas subversivas, creando de rebote un clima de aparente normalidad. Es preciso añadir, entre las otras fuentes que alimentaron el mercado boyante de la novela popular española, traducciones de títulos publicados por la Maison de la Bonne Presse ${ }^{13}$, grupo fundado en

\footnotetext{
${ }^{10}$ El título Bonheur méconnu de Mary Floran (Paris, Petit Écho de la Mode, Collection Stella, n. ${ }^{\circ}$ 142, 1926), publicado anteriormente en la editorial Calmann Lévy en 1894, fue traducido primero con el título de Dicha ignorada (Barcelona, Eugenio Subirana, Colección «Princesa» n. ${ }^{\circ}$ XXXV, 1928, 222 pp. NB: las comillas aparecen en la presentación de la colección); se titula en la Biblioteca Rocío Dicha inapreciada (BR, n. ${ }^{\circ}$ 139). Otro ejemplo: Le Double jeu de Gaston de Wailly (Paris, Petit Écho de la Mode, Collection Stella n. ${ }^{\circ}$ 101, 1924), traducido al español como La doble farsa (Barcelona, Eugenio Subirana, Colección «Princesa» n. ${ }^{\circ}$ 20, 1925, 302 pp.) lleva finalmente el título de Con las mismas armas (BR, n. $\left.{ }^{\circ} 23\right)$.

${ }^{11}$ La colección consta de quinientos noventa y nueve títulos. Se puede calcular que entre los años 1919, cuando arranca dicha colección, y 1933, final de la publicación de la Colección «Princesa», se habían publicado alrededor de 179 títulos de la colección Stella, o sea que no faltaba materia prima por traducir.

${ }^{12}$ Texto publicitario reproducido por Ellen Constans en Ouvrières des lettres (Limoges, Presses universitaires de Limoges, 2007, p. 121).

${ }^{13}$ Es el caso de la novela Ninón [BR, n. ${ }^{\circ}$ 10], publicada primero en París en 1923 por la editorial Maison de la Bonne Presse, bajo el título Ninon-Rosa, y un año más tarde por Eugenio Subirana en la Colección «Princesa» [n. $\left.{ }^{\circ} \mathrm{XV}\right]$.
} 
1873 para contribuir al movimiento de restauración religiosa y social afirmando una presencia católica en el sector editorial ${ }^{14}$.

\section{Narrativa católica}

El secreto de Kernic, primer título de la Biblioteca Rocío, da la tónica general. Firmado por Pablo [Paul] Segonzac -siguiendo una costumbre antigua se ha españolizado su nombre como el de otros escritores/as- y publicado por primera vez en España en $1925^{15}$, la novela transporta al lector a Bretaña donde sigue las aventuras del nieto de unos industriales de la muy selecta ciudad de Neuilly ${ }^{16}$. El exotismo y la atemporalidad de la acción son garantes de la neutralidad ideológica y del escapismo literario. Para poner otro ejemplo de los temas abordados, basta leer la reseña de una de esas novelas publicada en un periódico católico toledano, El Castellano, con ocasión de su primera salida en la Colección Princesa en 1925:

La gentil Luciana Valleret, rica heredera, hastiada de ver que a ella se dirigen los pretendientes al acicate de sus rentas, decide escoger por sí misma su futuro esposo estudiando sus condiciones físicas y morales. A ese fin trama una farsa, en la que el pretendiente que debe ser observado, que abriga los mismos propósitos que Luciana, logra sagazmente hacer caer a la muchacha en la propia situación que ella preparaba. Y el amor, finalmente da fin a «La doble farsa». Interés, ingenio, emoción, sana y brillante literatura, he aquí los méritos de esta singular novela. ${ }^{17}$

La alta burguesía o la aristocracia a menudo retratadas encarnan la despreocupación por lo cotidiano y sobre todo el respeto por la tradición. Ingredientes recurrentes en la mayor parte de las reediciones de autores franceses, quienes pertenecen a una corriente que no podía sino interesar a Juan Bautista Viza: la narrativa católica. Recordemos que en Francia, después de la derrota de Sedan en 1870, las autoridades eclesiásticas y los medios políticos e intelectuales conservadores se valieron del género novelesco para contrarrestar el proceso de laicización fomentado por la III República. Folletines insertados en revistas baratas y de gran tirada ${ }^{18}$, novelas por entregas o novelas completas facilitaron la captación de lectores invitados a compartir los valores de la religión y la moral cristianas. Por consiguiente, no es nada extraño que encontremos en la Biblioteca Rocío a algunos de los grandes maestros de esta narrativa, mujeres las más veces a pesar de sus seudónimos masculinos: Guy Wirta, Mathilde Alanic, Jeanne de Coulomb, Henri Ardel, Pierre Alciette, Jean de la Brète, Alice Pujo, Mary Floran, Florence O’Noll, Gaston de Wailly, Jacques des Gachons y, sin duda el más exitoso, Delly, seudónimo detrás del cual se esconden hermano y hermana, autores de más de cien novelas que fueron

\footnotetext{
${ }^{14}$ Maison de la Bonne Presse saca, desde su creación, un boletín de las peregrinaciones (Lourdes, Notre Dame de La Sallette) titulado Le Pèlerin que aún existe bajo la forma de un semanal de información general cuya tirada supera los 250000 ejemplares. Maison de la Bonne Presse cambió su nombre en 1969 para adoptar el de Bayard Presse, siendo Bayard el título de una de sus revistas juveniles lanzada en 1936.

15 Paul Segonzac, El secreto de Kernic (Fleur de Lys), versión de José Pugés, Colección «Princesa», n. ${ }^{\circ} 18$, Barcelona, Eugenio Subirana, 1925.

${ }^{16}$ Pablo Segonzac, El secreto de Kernic, BR, n. ${ }^{\circ} 1$.

${ }^{17}$ El Castellano, Toledo (21/VII/1925). La novela La doble farsa lleva otro título en la Biblioteca Rocío, cfr. nota n. ${ }^{\circ} 9$.

${ }^{18}$ L'Ouvrier (1861-1921) y Les Veillées des Chaumières (1871-1998). Cfr. Daniel Compère (dir.), Dictionnaire du roman populaire francophone, Nouveau Monde, 2007, pp. 83-84.
} 
leídas, ante todo por un público femenino, hasta bien entrados los años setenta, años en que la colección Harlequin los destronó ${ }^{19}$. La narrativa de Delly se caracteriza en general por su ultraconservadurismo católico - la ley francesa de separación de las Iglesias y del Estado adoptada en 1905 radicalizó sus posiciones- y su profundo recelo para con los obreros viciados por los maestros de la escuela laica, los jefes sindicalistas y los diputados socialistas o masones, como se puede comprobar en El Rey de los Andes, título presente en la colección que nos interesa ${ }^{20}$. Salvando las distancias cronológicas y geográficas, cabe subrayar que los enemigos de la naciente España nacionalcatólica no eran diferentes.

\section{«Novelas honestas»}

Todos los autores escogidos para figurar en la Biblioteca Rocío eran intachables desde el punto de vista de la moralidad de sus escritos. No por nada algunos procedían de la colección Les Romans honnêtes [Las Novelas honestas], creada a finales de los años 1830 por la editorial belga Casterman para premiar a los alumnos meritorios. Es el caso de Claire de Chandeneux y Guy de Chantepleure -en realidad otra mujer ${ }^{21}$, cuya lectura es encarecidamente recomendada por el abad Louis Béthléem (1869-1940) en un libro-guía de las conciencias cristianas titulado: Romans à lire et romans à proscrire: essai de classification au point de vue moral des principaux romans et romanciers de notre époque (1800-1904), regularmente ampliado a partir de su primera publicación en 1905 con tiradas que alcanzaron los 120.000 ejemplares $^{22}$. En él, el abad descartaba a Barbey d'Aurevilly por considerarlo «histérico», «sádico» y «diabólico», consideraba al Tío Goriot de Balzac como «fangoso», a Flaubert como «deslumbrante» pero «perverso», a Víctor Hugo como una lectura reservada a personas maduras y «por motivos serios» o a Proust como «particularmente repugnante» ${ }^{23}$. Frente a la modernidad narrativa, la novela rosa canónica venía a ser un baluarte saludable. A las dos escritoras anteriormente citadas (Chandeneux y Chantepleure) por granjearse el nihil obstat del censor eclesiástico, podemos añadir a la ya evocada Alice Pujo, hoy totalmente olvidada a pesar de haber sido

\footnotetext{
${ }^{19}$ El uso de un seudónimo para las mujeres escritoras es, a lo largo del siglo XIX, muy frecuente, por ser considerado el oficio de novelista impropio del sexo débil. Guy Wirta se llama en realidad Gabrielle Wiart (Wirta es un anagrama de Wiart) [BR, n. ${ }^{\text {os }} 10$ y 93]; Jeanne de Coulomb es el seudónimo utilizado por Cécile Marguerite Coulon de Lagrandval (1864-1945) [BR, n. ${ }^{\circ}$ 19]; Henri Ardel, el de Berthe Abraham (1863-1938) [BR, n. ${ }^{\circ s}$ 26, 30]; Pierre Alciette, el de una pareja: Raymond y Alice Vialatte [BR, n. $\left.{ }^{\circ} 45\right]$; Jean de la Brète, el seudónimo de Alice Cherbonnel $(1858-1945)$ [BR, n. ${ }^{\circ}$ 61, 81], Mary Floran, el de Marie Leclercq (1856-1934) [BR, n. $\left.{ }^{\circ s} 40,139\right]$. Detrás de Delly [BR, n. ${ }^{\circ}$ 28, 32, 38, 43, 49, 52, 55], encontramos a Marie Petitjean de La Rosière (1875-1947) y a su hermano Frédéric (1876-1949). Mathilde Alanic (1864-1948) [BR, n. ${ }^{\circ}$ 13], Mathilde Aigueperse (1854-1924) [BR, n. ${ }^{\circ} 36$ ], Alice Pujo (1865-1953) [BR, n. ${ }^{\circ}$ 85] y Florence O’Noll (1877-1932) [BR, n. ${ }^{\circ}$ 14], forman parte del pequeño grupo de escritoras que firman con su propio nombre. Gaston de Wailly (1857-1943) [BR n. $\left.{ }^{\text {os }} 23,27,42\right]$ y Jacques des Gachons (1868-1945) [BR, n. ${ }^{\circ}$ 20] son los escasos autores masculinos franceses presentes en la colección. Cfr. Daniel Compère (dir.), Dictionnaire du roman populaire francophone, op.cit., pp. 17-18.

${ }^{20} \mathrm{BR}, \mathrm{n} .^{\circ}$ 49. Publicado en Francia por primera vez en 1910 [Le Roi des Andes, Paris, Maison de la Bonne Presse], el título se publicó en 1932 por séptima vez en la Colección Princesa.

${ }^{21}$ Claire de Chandeneux es el seudónimo de Emma Bailly (1836-1881) [BR, n. ${ }^{\circ} 24$ ] y Guy de Chantepleure el de la señora de Dussap, nacida Jeanne-Caroline Violet (1870-1951) [BR, n. ${ }^{\circ}$ 6].

${ }^{22}$ Louis Bethléem, Romans à lire et romans à proscrire: essai de classification au point de vue moral des principaux romans et romanciers de notre époque (1800-1905), Cambrai, O. Masson, 1905. En 1928, en su décima edición, el abad abarcaba el período 1500-1928.

${ }^{23}$ Citado por Pascal Dibie, La Tribu sacrée: ethnologie des prêtres, Paris, Métaillé, 2004, p. 156.
} 
la guionista de las primeras láminas de Mon ami Pif en La Semaine de Suzette (12/IX/1928) ${ }^{24}$ y haber colaborado en L'Action Française -diario del partido reaccionario epónimo codirigido por su hermano- cuyas novelas estaban consideradas por el abad Béthléem como «llenas de encanto, de pintoresquismo y de pensamiento consolador» 25 .

El mismo elogio podía aplicarse al sentimentalismo cultivado por Magali o en menor medida por el que fue su primer marido, Marcel Idiers $^{26}$, porque nunca rebasa los límites de un decoro bienpensante. Sin embargo, la figura de Magali era susceptible de levantar algunas sospechas ya que la novelista alcanzó fama por vivir de su propia pluma en los años veinte y conoció un destino comparable con el de Colette - escribió como ella libros para su marido antes de dejarle- o con Carmen de Burgos, alias Colombine, por su gran independencia y su doble dedicación de escritora y periodista $^{27}$. Pero resulta evidente que las novelas reeditadas de Magali por la Biblioteca Rocío tampoco se alejaban de los acostumbrados códigos de la novela de amor por centrarse principalmente en la función de futura esposa de la mujer en ámbitos de lo más encopetados. El lector deseoso de buscar asomos de modernidad en sus novelas debe concluir que ésta se circunscribe a detalles como el que consiste en evocar la presencia cada vez más importante del jazz:

Sobre la cubierta florida cual un invernadero de «palace», casi todas las mesas de «bridge» están ocupadas, diseminadas entre las palmeras y las hortensias, como en islotes inabordables. Hacia el centro, en el espacio que se dejó libre, una pareja se agita, infatigable, a los sones de un invisible jazz [... ${ }^{28}$

\section{¿Inocuidad?}

El aprovechamiento de un fondo editorial -la Colección Princesa- ofrecía pues todas las garantías necesarias ya que, además de ser traducciones debidamente seleccionadas, las novelas habían sido publicadas por Eugenio Subirana, quien gozaba entonces del privilegio de ser editor pontificio -a este título encargado de publicar regularmente el Anuario eclesiástico- y por consiguiente muy atento a la ortodoxia de su catálogo ${ }^{29}$. Catálogo que conocía perfectamente el catalán Juan Bautista Viza y Caball, responsable de la Biblioteca Rocío, por haber colaborado en la editorial, entre otras cosas con una versión expurgada de una novela histórica sobre Jesucristo escrita por un escritor francé $^{30}$ y una traducción de un libro de un periodista, también francés, sobre la Italia fascista,

\footnotetext{
${ }^{24}$ En 1945, el dibujante español José Cabrero Arnal, exiliado político en Francia tras la Guerra Civil española y luego deportado a Mathausen, retomó el personaje de Pif para el periódico comunista L'Humanité.

${ }^{25}$ Pascal Dibie, La Tribu sacrée: ethnologie des prêtres, op. cit., p. 159.

${ }^{26}$ Jeanne Philbert (1898-1986) [BR, n. $\left.{ }^{\text {s }} 12,22,88,95\right]$ utilizó, además de Magali, una serie de seudónimos en la enorme cantidad de sus novelas (aproximadamente ciento cincuenta): Claude Desvalliers, Michel Cerdan, Michel de Surty, Sylvaine, André Curtis, Brigitte Ailly. Marcel Idiers, BR, n. ${ }^{\circ s}$ 60, 67, 70, 79, 90, 156.

${ }^{27}$ Durante la II Guerra Mundial participó en la Resistencia francesa fundando una editorial en Toulouse que, al tiempo que publicaba novelas rosas, se dedicaba a hacer falsa documentación, imprimía octavillas y periódicos clandestinos, $c f r$. Ellen Constans, Ouvrières des lettres, op. cit., p. 72.

${ }^{28}$ Magali, Corazones altivos (edición refundida), BR, n. ${ }^{\circ} 22$, p. 3.

${ }^{29}$ Eugenio Subirana (1856-1934) pertenece a una familia importante de editores al mismo tiempo que impresores y libreros católicos barceloneses. Además de la editorial ya citada, hay que señalar la de Viuda e hijos de J. Subirana y la de Hermanos Subirana, por lo visto ambas anteriores a la de Eugenio Subirana.

${ }^{30}$ Henry Dupuy Mazuel, Chrestos, versión española con notas aclaratorias de Juan Bautista Viza, Barcelona, [Imp. Subirana], 1934. La edición francesa es de 1933.
} 
verdadero modelo que seguir, según él, como veremos más adelante. Volviendo al elenco de escritores populares franceses que forman este fondo, conocidos ante todo por su conformismo, tanto literario como social, y por su moralismo sencillo, éste constituye una profesión de fe en la recuperación de modelos tradicionales, modelos que el aparato jurídico español había mantenido vigentes hasta la II República, considerada como responsable de todos los males de España por sus detractores. En efecto, teniendo en cuenta que se dirige principalmente a mujeres - los títulos así como las cubiertas son inequívocos ${ }^{31}$, el discurso vehiculado por esas novelas sentimentales o familiares, aunque son extranjeras y pertenecientes a otra época, está en total adecuación con los valores decimonónicos pregonados por los diferentes sectores rebeldes. La protagonista, joven mujer casadera, debe en general superar una serie de pruebas antes de ser premiada por el amor de un galán con el que termina casándose. Esas pruebas resultan ser por consiguiente el aprendizaje de su futuro papel de esposa, de madre y de ama de casa bajo la autoridad, sea paternal o marital, sea eclesiástica, cuando no emana de una figura política. Las novelas escenifican las reglas de buena conducta que deben adoptar las mujeres jóvenes con consejos que toman prestados de la propia Iglesia o de sus turiferarios. La ya citada Florence O'Noll admiraba sobremanera a la maestra de escuela y escritora Céline Fallet, autora de libros edificantes para la juventud y su educación tales como Éducation des jeunes filles: conseils aux mères de famille et aux institutrices ${ }^{32}$, libro de consejos para las muchachas, respetuosos del dogma católico, parecido a los que florecían en España en la misma época, firmados por eclesiásticos —el padre Antonio María Claret es prolífico en este généro- o por escritoras tales como Pilar Sinués, Faustina Sáez de Melgar o Pilar Pascual de Sanjuán, preocupadas todas por la perpetuación de un modelo social que las influencias extranjeras amenazaban ${ }^{33}$. Las novelas rosas francesas aparentemente inocuas de la Biblioteca Rocío, son en realidad vectores de una ideología retrógrada a la que naturalmente se adhieren los autores españoles presentes en la colección estudiada.

\section{Conservadurismo casero}

Una empresa literaria nacional tenía la obligación de privilegiar a escritores españoles. La omnipresencia de autores franceses, no obstante su evidente conservadurismo, podía acabar por ser cuestionada. En efecto, a pesar del Pacto de No Intervención, firmado por el gobierno de Léon Blum

\footnotetext{
${ }^{31}$ La mención en los títulos de las novelas de nombres de mujeres es frecuente: Ninón (Guy Wirta), Anita (Delly), Rosa Perrín (Alice Pujo). Del mismo modo, las temáticas amorosas son transparentes: Siempre vence el corazón (Mathilde Alanic), Corazones altivos (Magali), Una herencia y un amor (Gaston de Wailly), Cómo quiero ser amada (Henri Ardel), Amor, Amistad y Sacrificio (Pierre Alciette), etc. En cuanto a las cubiertas, suelen mostrar a mujeres de una belleza inalcanzable.

${ }^{32}$ Céline Fallet (1829-1887?), Éducation des jeunes filles: conseils aux mères de famille et aux institutrices, Paris, Librairie Classique de Perisse Frères, 1863.

${ }^{33}$ En la larga bibliografía del padre Claret (1807-1870), podemos citar Avisos saludables a las doncellas, o sea, carta espiritual que escribió a una hermana suya (1844) o La misión de la mujer que el Todopoderoso le ha confiado (1859). [María del] Pilar Sinués [de Marco] (1835-1893) publicó, por ejemplo, Un libro para las jóvenes (1879) e Hija, esposa y madre. Cartas dedicadas a la mujer acerca de sus deberes para con la familia y la sociedad (1864-1866); Faustina Sáez de Melgar (1834-1895) firmó Un libro para mis hijas. Educación cristiana y social (1877); y Pilar Pascual de Sanjuán (1827-1899) un Tratado de urbanidad para las niñas (1884) o Cartas morales de una maestra a una madre de familia (1875).
} 
en agosto de 1936, las remesas de armas procedentes de Francia, a las que habría que añadir la importante presencia de sus voluntarios acudidos en ayuda de la República (casi 9.000 en las Brigadas Internacionales, que alcanzaron la cifra de 35.000 combatientes), favorecieron un sentimiento antifrancés en la zona franquista. La publicación de autores españoles, confirmados o noveles, permitía salir al paso de las eventuales críticas. Una vez más, prevaleció la «blancura» del currículo de los elegidos y de su temática, donde se mezclan sentimentalismo y fervor religioso. Los literatos cuya trayectoria se puede reconstruir ${ }^{34}$ cumplían ampliamente estos requisitos. Juan Laguía Lliteras, traductor de varias novelas de la Colección «Princesa», por lo tanto conocedor de los resortes novelescos insoslayables -fase de exposición, nudo con las necesarias

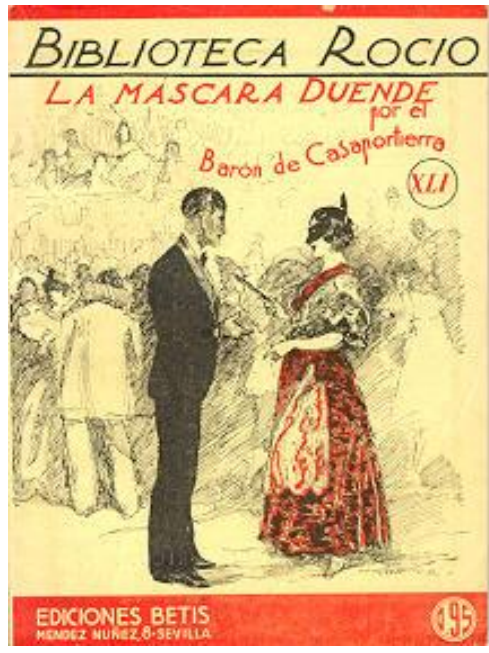

Barón de Casaportierra, La máscara duende, $B R, n .^{\circ} 41$ revelaciones y desenlace feliz- narra en su novela las penas de un príncipe de alta alcurnia, «Hans de Telse y de San Dolough, gran duque de Ancin, heredero de siete condados, primo hermano del rey», como mandaba la tradición, que «había entrado en la Compañia

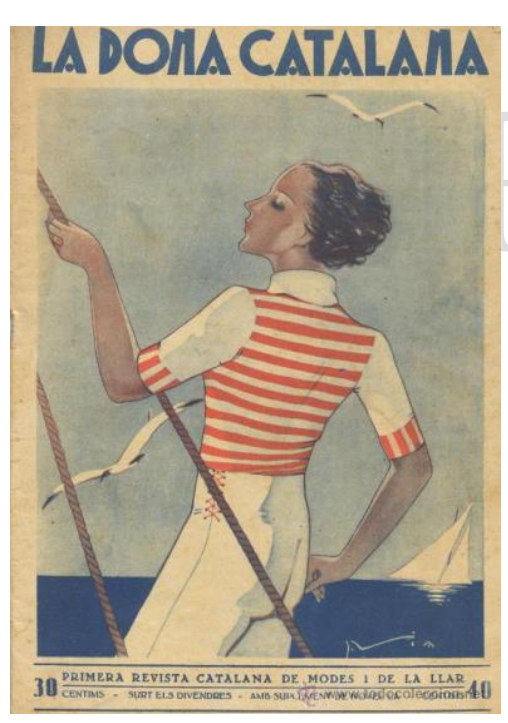

La Dona Catalana. Primera Revista catalana de modes $i$ de la llar, VI/1934 de Jesús, tras una gran desilusión de amor» ${ }^{35}$. Rafaelina del Corral y Vallejo, alias «El Barón de Casaportierra» ${ }^{36}$, se conocía ante todo por su misticismo y sus obras caritativas así como por sus episódicas colaboraciones en el periódico de obediencia católica El Debate. Primero independiente de todo partido político, este periódico se convirtió luego, en el período de la II República, en portavoz oficial de Acción Nacional -fundada en 1931 por Ángel Herrera Oria, tuvo que cambiar su nombre por el de Acción Popular- y a continuación de la CEDA (Confederación Española de Derechas Autónomas) ${ }^{37}$.

Otra presencia notable es la de Cristina Busquets cuya novela, El juramento de Fernando, había sido publicada primero en catalán por la Biblioteca La Dona Catalana ${ }^{38}$. La Dona Catalana fue primero una revista de moda barcelonesa vinculada con los sectores del catalanismo

\footnotetext{
${ }^{34}$ Ciertos autores dejaron pocos rastros. Es el caso de Martín Tena Sánchez (Por los caminos del Amor, BR, n. ${ }^{\circ}$ 54); tan sólo se puede encontrar que terminó en 1942 su licenciatura de Derecho en la universidad de Sevilla ( $A B C$, edición de Andalucía, «Ecos de sociedad», 20/VI/1942).

${ }^{35}$ Juan Llaguía Lliteras, El Rey que tuvo un solo amor, BR, n. ${ }^{\circ}$ 4, p. 3 . El autor tradujo, entre otros títulos, Ninón de Guy Wirta (Barcelona, Eugenio Subirana, Colección «Princesa»n. $\left.{ }^{\circ} 15,1924\right)$, A los dieciocho años de Mathilde Aigueperse (Barcelona, Eugenio Subirana, Colección «Princesa»n..$^{\circ}$ 7, 1923) y Lucila y el matrimonio de Pedro [Pierre] Alciette (Barcelona, Eugenio Subirana, Colección «Princesa»n. $\left..^{\circ} 41,1929\right)$.

${ }^{36}$ Rafaelina del Corral y Vallejo (1897-1965) firmaba también sus escritos «Miss Nadie». Las novelas suyas publicadas en Biblioteca Rocío son El cantar de la muerta (n. $\left.{ }^{\circ} 29\right)$ y La máscara duende (n. $\left.{ }^{\circ} 41\right)$.

${ }^{37}$ Cfr. María Cruz Seoane y María Dolores Sáiz, Historia del periodismo en España. 3 El siglo XX: 1898-1936, Madrid, Alianza, 1996, pp. 118-120.

${ }^{38}$ Cristina Busquets, El jurament de Ferran, Barcelona, Bosch, Biblioteca La Dona Catalana [¿1935?]; El juramento de Fernando, BR, n. ${ }^{\circ}$ 25. Firma también El collar de Rosalinda, BR, n. ${ }^{\circ} 17$.
} 
conservador -en particular la Lliga Regionalista- adeptos del modelo femenino noucentista de La ben plantada [La bien plantada] tal y como la definía Eugeni d'Ors ${ }^{39}$. Además de noticias relacionadas con la moda, de labores de costura y demás patrones, La Dona Catalana tenía una sección infantil y páginas literarias compuestas por un folletín y un suplemento de dieciséis páginas, el cual, al cabo de cierto tiempo, formaba una novela completa que integraba luego la Biblioteca La Dona Catalana, colección compuesta, según la publicidad que se hizo de ella, de «novelas de sana literatura y que pueden ser leídas por todos» ${ }^{40}$. Entiéndase una literatura que debía infundir sentimientos religiosos, como lo recalcaba en el diario $A B C$ de Sevilla la reseña-reclamo dedicada a $E l$ collar de Rosalinda ${ }^{41}$, la segunda novela de Cristina Busquets ${ }^{42}$ :

Una delicada historia de sacrificios y sufrimientos ha dado argumento a la distinguida escritora Cristina Busquets para crear una interesantísima novela que se lee con avidez, pues la atención del lector se halla cautivada en todos momentos por los imprevistos episodios que se producen. La protagonista que, desde las primeras páginas del libro, despierta la simpatía y afecto del lector, logra después de un calvario de humillaciones y desprecios la reivindicación más perfecta y el amor sincero y desinteresado del hombre amado.

Y, para remachar el clavo, en la cubierta de la novela, se

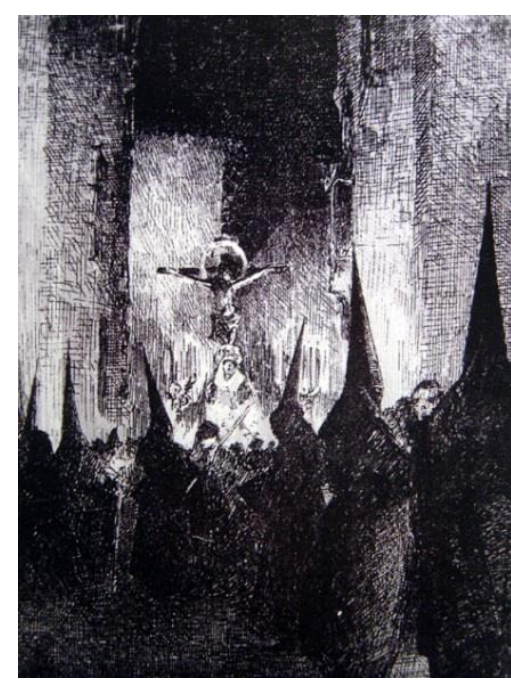
reproduce una pintura de tema religioso del pintor costumbrista andaluz Francisco Hohenleiter de Castro, conocido en los años 20 por sus representaciones de la Semana $\mathrm{Santa}^{43}$. Religiosidad reafirmada también por otro símbolo Francisco Hohenleiter de Castro, Santa
Cruz por su barrio, 1930 presente en los primeros números de la Biblioteca Rocío: la Giralda de la catedral de Sevilla.

\section{Antídoto contra la subversión}

Esa literatura, supuestamente sana, todavía vigente en los años de la Guerra Civil, entendía luchar contra el paganismo creciente denunciado por la colaboradora regular de la Biblioteca Rocío María Sepúlveda, como se puede comprobar en un artículo suyo publicado algunos años antes en las páginas de El Universo. Revista de Acción Católica y de Cultura General:

La cristiandad de nuestros días se ha dejado vencer por un paganismo que, inconscientemente asimilado por unos, predicado por otros, ha venido a renovar en parte el triste espectáculo de aquellas sociedades de la Antigüedad [...]. ${ }^{44}$

\footnotetext{
${ }^{39}$ Xenius, La ben plantada, Barcelona, Imprenta Joaquim Horta, $2^{\mathrm{a}}$ ed., 1911.

40 «[N]ovel-les de sana literatura i que pugim ésser llegides per tothom», La Dona Catalana, n. ${ }^{\circ}$ 181, març 1929 , p. 1.

${ }^{41}$ No hemos podido determinar si se trataba de una reedición o de un texto inédito.

${ }^{42} A B C$ de Sevilla (26/VI/1938).

${ }^{43}$ Se puede ver también en la portada del n. ${ }^{\circ} 15$ una reproducción de una obra de Hohenleiter que representa la capilla de la basílica sevillana de Jesús del Gran Poder.

${ }^{44}$ María Sepúlveda, «La mujer cristiana en el siglo IV», El Universo. Revista de Acción Católica y de Cultura General, 47 (25/III/1927), artículo citado por Rebeca Arce Pinedo, Dios Patria y hogar. La construcción social de la mujer española
} 
Para hacer frente a los ataques laicistas, María Sepúlveda compaginó su actividad en la Acción Católica de La Mujer (1919) con su oficio de novelista. Su objetivo era dar un rumbo al bello sexo que se podría resumir de la manera siguiente: rezar, trabajar, obedecer y amar. María Sepúlveda participó así en el esfuerzo de la Iglesia por controlar la sociedad y oponerse a la literatura licenciosa tanto como a la literatura política en pleno auge. Ambición compartida por la Biblioteca Rocío que propone en un primer tiempo tres reediciones de esta autora -Dos vidas, Un caso singular y Revelación ${ }^{45}$, procedentes de la muy católica Biblioteca Patria de Obras Premiadas que se presentaba a sí misma como «obra de saneamiento literario» ${ }^{46}$ en colaboración con el Patronato Social de Buenas Lecturas, cuya razón social se encontraba en Córdoba, ciudad donde aquélla proseguiría su trabajo durante la contienda ${ }^{47}$. A este respecto, hace falta subrayar que el tema de la Guerra Civil está ausente de los numerosos textos inéditos propuestos luego por María Sepúlveda que sin embargo lo abordó en otras ocasiones $^{48}$. Se podría decir otro tanto de la entonces famosa Concha Espina que por su estancia forzosa en la zona roja encarnaba la resistencia contra la «hidra marxista» según la expresión acuñada en la zona sublevada. Melchor Fernández Almagro, colaborador en varias revistas falangistas (Vértice, $F E$ ), crítico para el $A B C$ de Sevilla, sabía todo el partido que se podía sacar de la prosa de Concha Espina, aunque no estuviera ambientada en la Guerra Civil. Su reseña de El hombre y el mastín impone una interpretación de tipo político:

La fábula se complica con un claro y persuasivo simbolismo político. Una pastorcita está a punto de caer en la tentación brutal del amor y de las ideas con que la asedia un minero envilecido. Pero no cae. Se cifra en este idilio de dramático y providencial desenlace, el problema de la cándida población campesina, cuando la invade con sus venenos y peligrosos estímulos el proletariado industrial: extraviado, no más culto. Tema por cierto, genuinamente cantábrico, porque en tierras castellanas o andaluzas no se puede dar, en cuantía semejante, ese fenómeno de competencia, política y económica entre la «aldea perdida» y la mina o la fábrica. ${ }^{49}$

Otro caso ejemplar del estricto control de los novelistas es el de Gustavo del Barco cuya obra Los forjadores de la Nueva España, recomendada por la Iglesia, la cual a cambio de su apoyo a la sublevación había obtenido el control de la educación, figuraba en la lista de los libros imprescindibles

por el catolicismo y las derechas en el primer tercio del siglo XX, Santander, Ediciones Universidad de Cantabria, 2007, p. 114.

${ }^{45}$ María Sepúlveda, Dos vidas, Madrid, [sn, sa], Biblioteca Patria de Obras Premiadas, n. ${ }^{\circ} 284$ [¿193-?]; BR, n. 31. Revelación, Barcelona, Juventud, 1929; Madrid, [sn, sa], Biblioteca Patria de Obras Premiadas, n. ${ }^{\circ} 226$ [i192-?]; BR, n. ${ }^{\circ}$ 37. Caso singular, Madrid, Biblioteca Patria de Obras Premiadas n. ${ }^{\circ} 302$ [¿192-?]; Un caso singular, BR, n. ${ }^{\circ} 53$.

${ }^{46}$ Cfr. Juan Carlos Sánchez Illán, «Edición del libro religioso», en Jesús A. Martínez (dir.), Historia de la edición en España (1836-1936), Madrid, Marcial Pons, 2001, pp. 354-372. Según el autor, la Biblioteca Patria publicó trescientos diecinueve volúmenes entre 1904 y 1939.

${ }^{47} \mathrm{La}$ Biblioteca Patria sacó a luz una novela ambientada en la Guerra Civil de Carmen Carriedo de Ruiz titulada En plena epopeya, Córdoba, Imprenta la Española, Biblioteca Patria de Obras Premiadas, n. ${ }^{\circ} 317$ [¿1937?].

${ }^{48}$ María Sepúlveda, Contra sí misma, BR, n. ${ }^{\circ} 63 ;$ La gran lección, $\mathrm{BR}, \mathrm{n} .{ }^{\circ} 82 ;$ A pesar de todo, $\mathrm{BR}, \mathrm{n} .{ }^{\circ}$ 102; La sombra de un pasado, BR, n. ${ }^{\circ} 133 ;$ El otro amor, BR, n. ${ }^{\circ} 143$. Tratará de la Guerra Civil en En la gloria de aquel amanecer, Córdoba, Nueva España, 1937; en Triunfo, Córdoba, Nueva España, 1938; y en Una mujercita fuerte y animosa, San Sebastián, Editorial Española, 1938. Para completar estos datos, se pueden añadir las «novelas» y novelas cortas publicadas en la revista de género policíaco, Letras, realizada en Zaragoza: Liberación, Letras, n. ${ }^{\circ} 18$ (I/1939), pp. 71-77; Viñetas de la revolución marxista (Novela corta), Letras, n. $^{\circ} 22$ (V/1939), pp. 23-43; Contraste, Letras, n. ${ }^{\circ} 24$ (VII/1939), pp. 17-63.

${ }^{49} A B C$ de Sevilla (12/VIII/1939). Concha Espina, Cura de amor, BR, n. ${ }^{\circ} 59 ;$ El hombre y el mastín, BR, n. ${ }^{\circ} 73$. 
para la instrucción de los alumnos al igual que las fábulas de Iriarte o Samaniego o del Quijote $^{50}$. Su firma fue regular en la Biblioteca Rocío, donde publicó por lo menos catorce novelas sin vínculo con el conflicto $^{51}$.

A falta de textos inéditos o de textos que novelen la Guerra Civil -veremos más adelante que no faltan a pesar de la declaración programática de Juan Bautista Viza- la Biblioteca Rocío desempeña la función de vitrina de la gente de letras que se comprometió incondicionalmente con los golpistas. Así es como, al lado de Concha Espina, encontramos al renombrado dramaturgo Eduardo Marquina o al no menos famoso intelectual monárquico José María Pemán. De

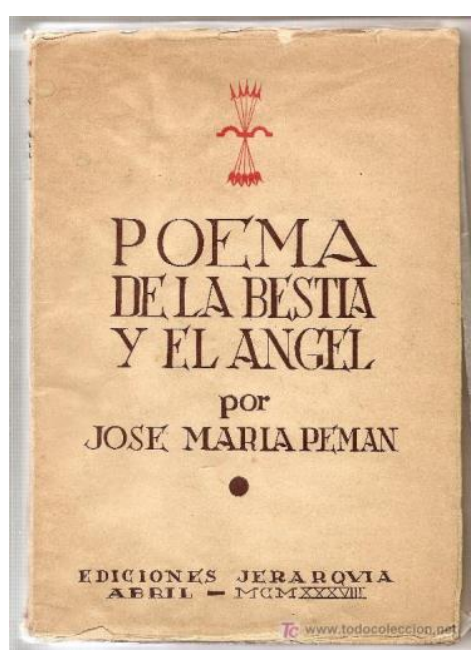
Eduardo Marquina -se encontraba en Buenos Aires al estallar la Guerra Civil e hizo propaganda en Perú y Chile a favor de los «nacionales»- se reedita la novela El destino cruel, publicada en 1920 en la colección La Novela Corta ${ }^{52}$. De José María Pemán, considerado como bardo oficial del Alzamiento tras la publicación de su Poema de José María Pemán, Poema de la
bestia y el ángel, Zaragoza,
Jerarquía, 1938 la Bestia y el Ángel ${ }^{53}$, se reedita una obra de teatro (Julieta y Romeo)

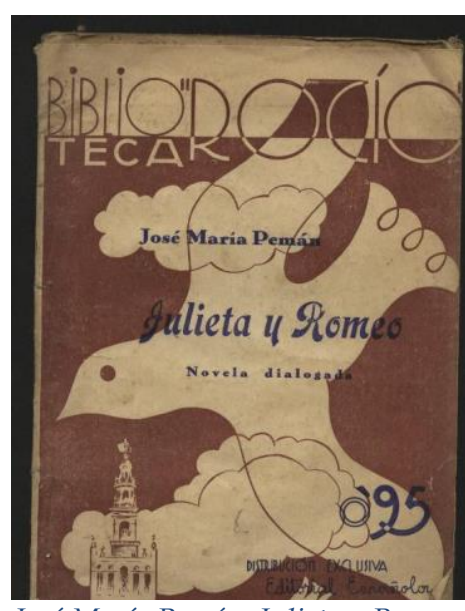

José María Pemán, Julieta y Romeo. Novela dialogada, BR, $n^{\circ} 3$ estrenada en 1935, como se puede leer en la portada, subtitulada para encajar en el molde editorial Novela dialogada, y dos textos narrativos (Fierabrás y Estampas románticas) difundidos en 1927 por La Novela Hispano-Americana, colección que estaba en la órbita de la prensa católica -se distribuía en Madrid en el quiosco de El Debate, periódico evocado anteriormente-, y cuya pretensión era «moralizar nuestra literatura limpiándola de tanto cieno, de extravagancias y de excitaciones voluptuosas» ${ }^{54}$.

El primer texto, sin duda el más interesante ${ }^{55}$, debido a las circunstancias bélicas, se desarrolla en una Casa del Pueblo, lugar de sociabilidad obrera por definición, donde impera el Presidente del

${ }^{50}$ Boletín Oficial del Estado, Burgos (22/III/1938).

${ }^{51}$ El mejor Médico: Amor, BR, n. ${ }^{\circ}$ 40; Tú y la Giralda, BR, n. ${ }^{\circ} 46 ;$ La casa de las lágrimas, $\mathrm{BR}, \mathrm{n} .^{\circ} 71 ;$ Sahra, $\mathrm{BR}, \mathrm{n} .^{\circ} 74 ;$ El maestro rural, BR, n. ${ }^{\circ} 83$; Ella y Él: Tú y Yo, BR, n. ${ }^{\circ} 87$; La cómica, BR, n. ${ }^{\circ} 91 ;$ El hombre que volvió a nacer, $\mathrm{BR}$, n. ${ }^{\circ}$ 97; Confidencias (Memorias de la Princesa María Fernanda), BR, n. ${ }^{\circ} 103 ;$ La vida es esto, $\mathrm{BR}, \mathrm{n} .^{\circ}$ 108; Una periodista, BR, n. ${ }^{\circ}$ 140; El Príncipe Pablo, BR, n. ${ }^{\circ} 161$; La Ría Inaga, BR, n. ${ }^{\circ} 171$; Un manojo de cartas, BR,.$^{\circ} 187$.

${ }^{52}$ Eduardo Marquina, El Destino cruel, Madrid, Prensa Popular, La Novela Corta, n. ${ }^{\circ} 252,1920$. El título de esta novela pierde su artículo definido en la Biblioteca Rocío, BR, n. ${ }^{\circ} 64$.

53 José María Pemán, Poema de la Bestia y el Ángel, Zaragoza, Jerarquía (Gráficas Uriarte), 1938, ilustraciones de Carlos Saénz de Tejada; Julieta y Romeo. Comedieta en prosa, Madrid, Manuel Herrera Oria, imp. Ribadeneyra, 1936; El vuelo inmóvil, Madrid, Editores Reunidos, La Novela de Una Hora, año 1, n. ${ }^{\circ} 11$ (15/V/1936). Julieta y Romeo (Novela dialogada) y El vuelo inmóvil forman una misma entrega de la Biblioteca Rocío, BR, n. ${ }^{\circ}$ 3. Fierabrás, Valencia, Tipografía Moderna, La Novela Hispano-Americana, año, 1, n. ${ }^{\circ} 2$ (20/III/1927). Estampas románticas, Valencia, La Novela HispanoAmericana, año $1, \mathrm{n} .{ }^{\circ} 11,1927$ se reedita en BR, n. ${ }^{\circ} 21$ seguido de la novela corta Por eso.

${ }^{54}$ Cfr. Cecilio Alonso y Claire-Nicole Robin, «Series periódicas de narraciones breves», Cultura Escrita y Sociedad, 5 , Gijón, Ediciones Trea (IX/2007), pp. 198-199.

55 Estampas románticas narra los recuerdos ingenuos de un niño acerca de su tía Eloisa. 
Sindicato de la Sal, un tal Donato Crespo, apodado «Fierabrás» por su demagogia. José María Pemán expresa un desprecio aristocrático para con el pueblo y el movimiento obrero. Del responsable de la Casa del Pueblo escribe que «Había recorrido durante su vida todo el escalafón porteril: botones, portero, ujier, conserje», y se vale de una imagen poco halagüena para referirse a los habituados del lugar: «En seguida, la ancha puerta bodeguera empezó a vomitar una masa informe y sudosa de blusas azules y chaquetas de dril [...]» ${ }^{56}$. Fierabrás, condenado por su deseo de ascenso social, termina como agente de la circulación en Madrid ${ }^{57}$. En Por eso, la novela corta que concluye la misma entrega de la Biblioteca Rocío, Pemán vuelve a clamar su defensa del statu quo social considerando la Guerra Civil como una solución a los males de España encarnados por los republicanos. Gonzalo de Herrera, capitán de cuarenta años, «jubilado de Azaña» y antiparlamentario -como su autor, quien sin embargo salió diputado monárquico por Cádiz en las elecciones de noviembre de 1933- es destinado a la censura del teléfono, oficio poco acorde con su carrera militar. Como era de esperar, el oficial antirrepublicano no se satisface con esa vida de oficinista que le obliga a interesarse por «diálogos de amor, "flirteos", riñas de matrimonios, comadreos de mujeres ${ }^{58}$. Afortunadamente, la sublevación militar de 1936, que él bendice, le permite volver a ostentar sus cualidades castrenses. Para sacrificar al género sentimental el protagonista se enamora de una enfermera, pero José María Pemán, sin duda molesto por tratar temas livianos en un momento que requería una total entrega a la causa de los sublevados, precipita el desenlace final dejando algo perplejo al lector acostumbrado a más detenimiento en tales circunstancias. Así es como termina la novela corta:

Se encontraron en San Sebastián. La guerra acelera los sucesos y evita trámites y complicaciones superfluas. [...] Al cabo de un mes se casaron [...]. La guerra con su prisa revolucionaria, se lo había enseñado. No era el amor... ¡Qué pamplina! Era... ¿qué sé yo...? ¡Eso! ${ }^{59}$

Vemos con Pemán que la demostración según la cual Amor y Guerra Civil pueden compaginarse es aún muy tímida. Esa demostración la aportan con mucha más nitidez un conjunto de ocho novelas cuyos autores sacan provecho de un molde popular para participar en el esfuerzo propagandístico «nacional».

\section{Núcleo tradicionalista}

Las novelas que tratan sobre la Guerra Civil se publicaron mayoritariamente durante ésta y fueron obra de literatos conocidos por sus ideas derechistas o ultraderechistas. Juan Bautista Viza, principal promotor de la Biblioteca Rocío, autor de dos novelas, La mochila del soldado (novela de guerra) y Rosa-roja y flor de Lis (novela de revolución y de guerra) ${ }^{60}$, fue miembro del reaccionario

\footnotetext{
${ }^{56}$ José María Pemán, Fierabrás, BR, n. ${ }^{\circ} 21$, respectivamente p. 10 y p. 12.

${ }^{57}$ Menos caricaturesco es Héctor Vinuesa, el taxidermista de la novela corta El vuelo inmóvil, que no deja sin embargo de cultivar paradojas en su rechazo conjunto de la montería, del latifundio y de la reforma agraria (BR, n. ${ }^{\circ} 21$, p. 64).

${ }^{58} \mathrm{BR}, \mathrm{n}^{\circ} 21, \mathrm{p} .65$.

${ }^{59} \mathrm{BR}, \mathrm{n} .{ }^{\circ} 21, \mathrm{p} .74$.

${ }^{60}$ Respectivamente BR, n. ${ }^{\text {os }} 5$ y 11 .
} 
Partido Agrario Español opuesto a la reforma agraria y admirador del fascismo italiano. Concepción Castella de Zavala, la más prolífica de este grupo por firmar tres textos ambientados en el enfrentamiento (Guerra en el frente, paz en las almas, Hágase tu voluntad y La Rosa del Maestrazgo ${ }^{61}$ ), dejó siempre bien claro su compromiso carlista a pesar de las turbulencias por las que éste atravesó a raíz del Decreto de Unificación. En 1949, Manuel Fal Conde, el que fuera líder en Andalucía del carlismo, un tiempo exiliado en Portugal por Franco a causa de su insumisión, apadrinó al hijo de la escritora el día de su boda ${ }^{62}$. Jorge Villarín, autor de $L a$ enfermera de Ondárroa ${ }^{63}$, dedicó en 1935 una biografía apasionada

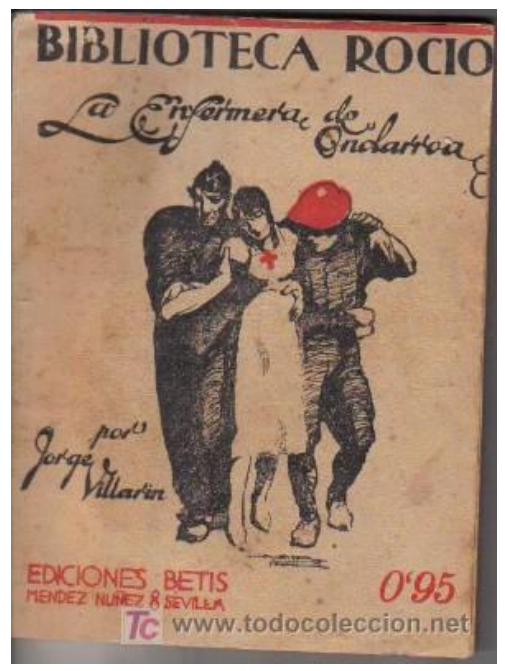
al mismo Fal Conde prologada por el conde de Rodezno, otra gran figura carlista ${ }^{64}$.

Antonio Pérez de Olaguer, presente en la Biblioteca Rocío con Amor y sangre (novela de estos tiempos de guerra) ${ }^{65}$, publicó en Jorge Villarín, La enfermera de Ondárroa, $B R, n^{\circ} 9$ plena Guerra Civil varios libros sobre el terror rojo y obras con ambición historiográfica para glorificar la gesta carlista ${ }^{66}$. Por fin, hace falta mencionar a Ramón Solsona y Cardona con Por mi Patria y por mi dama que, si bien parece ser escritor ocasional, se adhiere por completo a la línea ideológica de los autores ya citados al entonar, por la boca de una de sus protagonistas que agoniza, «un fuerte viva Cristo Rey» ${ }^{67}$. Estos autores no reparan en mezclar los géneros literarios para atraerse los favores del lector: novela de capa y espada, novela romántica, novela burguesa, novela rosa, etc. Se valen asimismo de recursos y elementos narrativos probados: la revelación -son frecuentes los personajes disfrazados-, la «virgen manchada»-huérfanas o muchachas purírismas violentadas por rojos con el consecutivo pathos-o la conversión benéfica de malvados que se sacrifican para el triunfo de la causa «nacional»son algunos de ellos. Además de su dimensión estética, todas estas obras comulgan en la celebración de las virtudes carlistas y proponen una verdadera mística que puede hacer émulos. Así es como ponen énfasis en el ambiente deletéreo de la ciudad -Barcelona en particular-donde se respira «el empozoñado hálito del marxismo» frente al aire regenerador del campo, sobre todo cuando se trata de Navarra, cuna del carlismo, donde «La vida campesina, la alimentación sana y la compañía de aquellas gentes honradas» permiten «un renacer de

\footnotetext{
${ }^{61}$ Colabora con otros títulos sin relación con la Guerra Civil: La hija de la Alhambra, BR, ${ }^{\circ}{ }^{\circ} 33 ;$ Santina, $\mathrm{BR}, \mathrm{n} .^{\circ}$ 68; y Dogal de oro, BR, n. ${ }^{\circ} 94$.

${ }^{62}$ Manuel Fal Conde no asistió sin embargo al enlace y fue representado por el marqués de Santa Rosa, $c f r$. $A B C$, edición de Andalucía (17/11/1949). Es de notar que el hijo de Concepción Castella de Zavala, José María de Zavala, llegó a ser Secretario general del Partido Carlista en 1966.

${ }^{63} \mathrm{BR}, \mathrm{n} .{ }^{\circ}$ 9. Había publicado anteriormente un texto narrativo titulado El romance de Ana María, BR, n. ${ }^{\circ} 2$.

${ }^{64}$ Jorge Villarín y Willy [seudónimo de Guillermo Poole miembro directivo del Partido Integrista en Sevilla], El secretario de su S. M., Sevilla, Álvarez Zambrano, 1935. El conde de Rodezno, tras la eliminación de Fal Conde por Franco, fue nombrado ministro de la Justicia en el primer gobierno franquista (1938).

${ }^{65} \mathrm{BR}, \mathrm{n} .{ }^{\circ} 8$.

${ }^{66}$ Cfr. José María Martínez Cachero, Liras entre lanzas. Historia de la literatura «nacional» en la Guerra Civil, Madrid, Castalia, 2009, p. 18.

${ }^{67}$ BR, n. ${ }^{\circ} 16$, p. 39.
} 


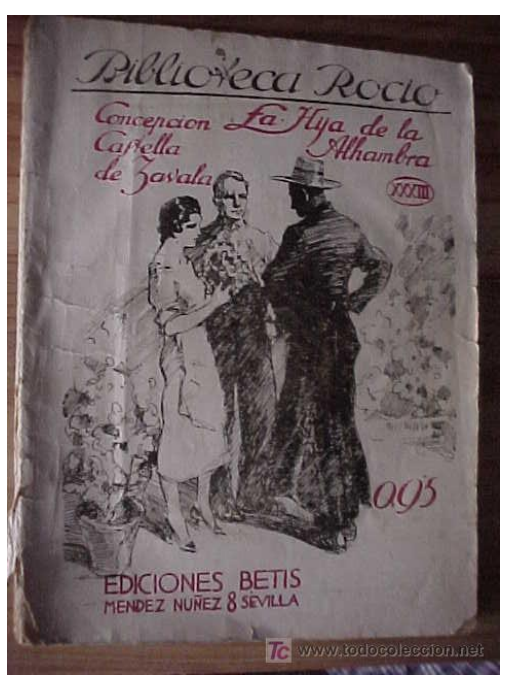

Concepción Castella de Zavala, La hija de la Alhambra, BR, $n^{\circ} 33$ la vida» de un personaje femenino de Concepción Castella de Zavala cuya pureza está cifrada en manos parecidas a las de Santa Teresa de Ávila. El puntal de este ideario es un agro bucólico que, según la misma escritora, garantiza el porvenir de España. Imbuida de estos valores, una muchacha se dirige a su amado convaleciente en un hospital con las siguientes palabras:

Cuando termine la guerra y vuelvas vencedor seremos felices; cuidarás tu hacienda y seremos campesinos. Primero ganarás a España con las armas; después con el arado. ${ }^{68}$

Al mismo tiempo, este ámbito rural aleja a la mujer de la frivolidad urbana y de sus peligrosos señuelos. Frente a la modernidad cosmopolita y atea se esgrime el banderín de la tradición autóctona y católica compendiada en personajes históricos invocados por su ilustre abolengo tales como Tomás de Zumalacárregui, famoso general carlista de la Primera Guerra Carlista, Ramón Cabrera, alias el «Tigre del Maestrazgo», otra gran figura carlista decimonónica, o Rafael García Valiño, oficial carlista -fue ascendido a general- que acaudilló la Primera Brigada de Navarra durante la Guerra Civil. La omnipresencia de combatientes carlistas, los llamados requetés, y de homenajes a sus tercios en las novelas debe interpretarse como un canto del cisne de un grupo político que debe resolverse a aceptar en abril de 1937 un Decreto de Unificación, sinónimo de su disolución en el llamado Movimiento y de su subordinación a la Falange. Situación exacerbada en las provincias del sur donde Falange conoció un aumento de sus afiliados que dejó muy a la zaga a la Comunión Tradicionalista y originó frecuentes roces. El sentimiento de ser menoscabados se trasluce en particular en las palabras de los protagonistas de la novela de Antonio Pérez Olaguer, quienes, «en la zona dominada por la antipatria, esclavizada por Rusia» ${ }^{69}$, escuchan a escondidas Unión Radio de Sevilla. Si se emocionan al escuchar al poeta José María Pemán, al general Queipo de Llano en una sus «charlas» o a José Millán Astray alabando a Franco, el día de la radiodifusión de un discurso del líder carlista Manuel Fal Conde, dicen no entender por qué se habla tan poco de los requetés. Sentimiento de injusticia que explica la transcripción de una parte del discurso en cuestión:

Llego, al fin, lleno de satisfacción, porque he tenido la honra de haber entregado al Ejército cincuenta mil requetés, navarros, vizcaínos, guipuzcoanos, burgaleses, riojanos, aragoneses y castellanos de otras provincias, que en el frente de Guadarrama y en el Norte se están comportando como se comportaron siempre los carlistas. ${ }^{70}$

\footnotetext{
${ }^{68}$ Concepción Castella de Zavala, Guerra en el frente, paz en las almas, BR, n. ${ }^{\circ}$ 7, sucesivamente pp. 62,66 y 87.

${ }^{69} \mathrm{BR}, \mathrm{n} .{ }^{\circ} 8$, p. 51.

${ }^{70} \mathrm{BR}, \mathrm{n} .{ }^{\circ} 8$, p. 53.
} 
La constancia de los elogios de la superioridad moral pero también guerrera de los requetés ${ }^{71}$ respecto a sus «camaradas» falangistas es una reivindicación evidente de su derecho natural a sacar provecho de la sublevación militar. Sin embargo, tras la evicción de su líder Manuel Fal Conde y luego el diktat del Decreto de Unificación que deniega a la Comunión Tradicionalista cualquier preeminencia política, el alegato de este grupo de escritores se asemeja al último combate de algunos irreductibles cada vez más aislados en la Andalucía falangista.

\section{Eugenismo literario}

La Biblioteca Rocío es un exponente más del esfuerzo realizado en la zona nacional para mantener una actividad editorial en plena contienda ${ }^{72}$. Como hemos visto, el método utilizado fue muy a menudo el reciclaje de un fondo de novelas que ofrecían las suficientes garantías de ortodoxia en una bando donde reinaba la depuración literaria -se celebraron autos de fe «purificadores» de bibliotecas privadas o públicas-. Si bien se pueden rastrear algunos intrusos entre los numerosos escritores publicados como la catalana Regina Opisso, alias Rosa de $\mathrm{Nancy}^{73}$, autora de catorce novelas para $\mathrm{La}$ Novela Ideal, la serie libertaria de la familia Montseny, o Rodolphe Bringer que participó en la creación en 1915 del periódico satírico francés Le Canard enchaîné cuya línea editorial dista mucho de la de La Biblioteca Rocío ${ }^{74}$, no cabe duda de que todas las novelas editadas encajan en el proyecto general de las autoridades nacionales de hacer tabla rasa de las vanguardias artísticas reputadas deletéreas y acusadas de todos los males, en particular el de de haber facilitado, antes de la actuación fatal de la II República, la emancipación de la mujer. Para remediarlo era imprescindible vigilar sus lecturas y expurgarlas en caso de necesidad. En el diario $A B C$ de Sevilla fechado el 14 de mayo de 1938, en la sección «Noticias de libros y revistas. Informaciones y juicios», se pueden leer dos reseñas muy aleccionadoras que merecen una cita completa por su carácter programático. La primera se refiere a la novela de Concepción Castella de Zavala ya mencionada Hágase tu voluntad:

Concepción Castella de Zavala acaba de consolidar su nombre de inspirada novelista con la obra que acaba de publicar Biblioteca Rocío. El ambiente aristocrático y frívolo en que se desarrolla la primera parte del libro deslumbra a la protagonista de la novela y le impide descubrir dónde está la verdad y el amor sincero. Sólo cuando la adversidad le amarga la vida acierta a encontrar el verdadero camino y entregarse al único afecto que puede hacerla feliz.

\footnotetext{
71 «Los requetés [fueron] las tropas más eficaces de los nacionales tras el ejército de África, llegaban ahora a unos 60.000 hombres, de los cuales la mitad procedía de Navarra, cosa que hacía fanfarronear a los carlistas que decían que "Navarra había salvado a España”», (Antony Beevor, La Guerra Civil española, Madrid, Crítica, 2005, p. 289).

72 Según José María Martínez Cachero, «Sevilla descolló por su actividad cultural durante estos años [...]» (Liras entre lanzas, op. cit., p. 23).

${ }^{73}$ Rosa de Nancy, Milagro de amor, BR n. ${ }^{\circ}$ 56; La novia del mundo, BR, n. ${ }^{\circ} 92 ;$ El amor vendrá después, $\mathrm{BR} \mathrm{n} .{ }^{\circ} 128 ;$ Elena, BR, n. ${ }^{\circ}$ 159. Regina Opisso Sala de Lloréns (1879-1965) usó también los seudónimos de Rosa González, Teresa Guzmán y Diana Roldán para firmar novelas rosas. Los textos de Regina Opisso para La Novela Ideal son anteriores a la Guerra Civil. Sin embargo, es autora de textos narrativos breves relacionados con la contienda para otra colección literaria: La Semana Literaria Popular, que ve la luz en Valencia en 1937 [La hermana del soldado, n. ${ }^{\circ} 60$ (5/XI/1938); Epistolario de la novia: carta primera (5/XI/1938); Epistolario de la novia: carta segunda (12/XI/1938)]. Regina Opisso fue también conocida por sus colaboraciones en Renovación, el periódico de las Juventudes Socialistas de España, y en Estudios, revista anarquista ecléctica y vanguardista.

${ }^{74}$ Rodolphe Bringer, El sobrino de América, BR, n. ${ }^{\circ} 99$.
} 
La Biblioteca Rocío (1937-1939) o las virtudes de la novela rosa durante la Guerra Civil...

Episódicamente aparece en el libro una evocación al gesto heroico de los defensores de Santa María de la Cabeza, que, a pesar de no constituir la esencia del argumento, atrae y cautiva al lector por su emoción hondamente sentida.

Contiene el libro, además de su galanura de lenguaje, una serie de momentos de intriga e interés que lo hacen realmente atractivo.

En la cubierta aparece una deliciosa reproducción de la capilla sevillana de Jesús del Gran Poder, obra del reputado artista andaluz Hohenleiter.

La segunda reseña se dedica a una obra del psiquiatra Antonio Vallejo Nágera titulada Divagaciones intrascendentes:

Admirable es la labor que el doctor Vallejo Nágera ha emprendido en pro de la higiene de la Raza, bien desde el punto de vista científico como apunta en su reciente libro Eugenesia de la hispanidad, bien en las costumbres. A esto tiende su último libro Divagaciones instrascendentes.

El doctor Vallejo Nágera, con sencillez extraordinaria, transmite a sus lectores las mismas preocupaciones y las mismas sensaciones e inquietudes que él experimenta por una mejora racial y moral de España.

Este es el tercer libro que en lo que va del año 38 publica el doctor Vallejo Nágera. Los tres libros han sido publicados por la Editorial Española de San Sebastián que a su vez sabe seleccionar maestramente cuáles son las lecturas que en estas horas de reconstrucción convienen a España. ${ }^{75}$

Antonio Vallejo Nágera, a la sazón jefe de los Servicios Psiquiátricos Militares del bando nacional, nombrado en agosto del mismo año Director del Gabinete de Investigaciones Psicológicas de la Inspección de Campos de Concentración de Prisioneros de Guerra investigó el Biopsiquismo del Fanatismo Marxista -título de uno de sus informes-en brigadistas y demás presos, hombres y mujeres, procesados por actividades políticas, y llegó a dictaminar la existencia de factores genéticos que predisponían al individuo al marxismo ${ }^{76}$. Para luchar contra tal predisposición el psiquiatra recomendaba una higiene racial o, para parafrasear una de sus obras, una «eugenesia de la hispanidad» ${ }^{77}$ que tuvo como primera consecuencia la separación familiar de los hijos de presos políticos y su posterior desaparición. La publicación concomitante de ambas reseñas no es una simple casualidad. Antonio Vallejo Nágera entiende contribuir a la regeneración de la raza, y de hecho sus teorías orientarían la política penitenciaria del Nuevo Estado ${ }^{78}$. La Biblioteca Rocío ambicionó participar en la reconstrucción moral de España proponiendo lecturas -cabe incluir el pequeño número de narraciones ambientadas en la Guerra Civil que ensalzan el heroísmo carlista- depuradas de cualquier atisbo de subversión, siendo la mayor, en el caso de la mujer, el pretender acceder a la esfera pública. La Biblioteca Rocío que, acabada la contienda, estableció su redacción en Barcelona -siguió editándose en Sevilla-, es pues un buen ejemplo de empresa editorial concebida para ejercer un control

\footnotetext{
75 ABC de Sevilla, (14/V/1938), p. 15. Antonio Vallejo Nágera, Divagaciones intrascendentes, Valladolid, Talleres tipográficos Cuesta, 1938.

${ }^{76}$ Javier Bandrés y Rafael Llavona, «La psicología en los campos de concentración de Franco», Psicothema, 1996, 8/1, pp. 1-11.

${ }_{77}$ A. Vallejo Nágera [Doctor], Eugenesia de la hispanidad y regeneración de la raza, Burgos, Editorial Española, 1937 ([Zaragoza], Talleres Gráficos de El Noticiero).

${ }^{78}$ José María Ruiz Vargas, «Trauma y memoria de la Guerra Civil y de la dictadura franquista», Hispania Nova. Revista de Historia Contemporánea, 6, 2006, en http://hispanianova.rediris.es. Tras la Guerra Civil, Antonio Vallejo Nágera ocupó la cátedra de Psiquiatría de la Universidad de Madrid y fue una de las figuras más influyentes de la psiquiatría española hasta los años sesenta.
} 
42 Tropelías. Revista de Teoría de la Literatura y Literatura Comparada, 23 (2015)

\section{Didier Corderot}

ideológico estricto sobre sus lectores ${ }^{79}$ gracias a una literatura inofensiva o, mejor dicho, guardiana de los valores tradicionales consagrados por la naciente España franquista.

${ }^{79}$ A juzgar por las frecuentes reediciones de ciertos números, fueron numerosos. 
La Biblioteca Rocío (1937-1939) o las virtudes de la novela rosa durante la Guerra Civil...

Apéndice: Biblioteca Rocío

Relatos, Novelas, Aventuras

\begin{tabular}{|c|c|c|c|c|c|}
\hline número 80 & $\begin{array}{c}\text { Fecha posible } \\
\text { de } \\
\text { publicación; } \\
\text { datos } \\
\text { paratextuales }\end{array}$ & Autor & Título $^{81}$ & Páginas & $\begin{array}{l}\text { Número } \\
\text { total de } \\
\text { páginas }\end{array}$ \\
\hline $\begin{array}{c}1 \\
{[0,95 \text { pta. }]}\end{array}$ & [IV/1937] & $\begin{array}{l}\text { Pablo [Paul] de } \\
\text { Segonzac }\end{array}$ & $\begin{array}{l}\text { El secreto de Kernic } \\
\text { (nueva edición) }\end{array}$ & $3-93$ & 96 \\
\hline 2 & $\begin{array}{c}{[\mathrm{V} / 1937]} \\
\text { copyright } \\
1937\end{array}$ & $\begin{array}{c}\text { Antonio Pérez de } \\
\text { Olaguer }\end{array}$ & El romance de Ana María & $1-91$ & 96 \\
\hline 3 & $\begin{array}{c}\text { [VI/1937] } \\
\text { estrenada en } \\
\text { el Teatro } \\
\text { María } \\
\text { Lisarda, } \\
\text { Coliseum, de } \\
\text { Santander, la } \\
\text { tarde del } 27 \\
\text { de julio de } \\
1935\end{array}$ & José María Pemán & $\begin{array}{c}\text { Julieta y Romeo } \\
\text { (*Novela dialogada } \\
\text { dividida en tres actos; } \\
\text { nueva edición) } \\
\text { El vuelo inmóvil } \\
\text { (novela corta) }\end{array}$ & $\begin{array}{r}1-55 \\
57-93\end{array}$ & 96 \\
\hline 4 & $\begin{array}{c}\text { [VII/1937] } \\
\text { hoja de } \\
\text { censura: } \\
\text { entrada: } 16 \\
\text { de junio, } \\
\text { salida: } 18 \text { de } \\
\text { junio }\end{array}$ & $\begin{array}{c}\text { Juan Laguía } \\
\text { Lliteras }\end{array}$ & $\begin{array}{c}\text { El Rey que tuvo un solo } \\
\text { amor }\end{array}$ & $1-96$ & 96 \\
\hline 5 & $\begin{array}{c}{[\mathrm{VIII} / 1937]} \\
* \text { Sevilla Julio } \\
1937\end{array}$ & Juan Bautista Viza & $\begin{array}{c}\cdot \text {-La mochila del soldado* } \\
\text { (novela de guerra) }\end{array}$ & $1-94$ & 96 \\
\hline 6 & [IX/1937] & Guy de Chantepleure & El Duque que fue soldado & $1-80$ & $\begin{array}{c}80 \\
\text { (réed du } \\
\text { texte) }\end{array}$ \\
\hline 7 & {$[\mathrm{X} / 1937]$} & $\begin{array}{c}\text { Concepción Castella de } \\
\text { Zavala }\end{array}$ & $\begin{array}{c}\text {-Guerra en el frente, paz } \\
\text { en las almas }\end{array}$ & $1-92$ & 96 \\
\hline 8 & [XI/1937] & $\begin{array}{c}\text { Antonio Pérez de } \\
\text { Olaguer }\end{array}$ & $\begin{array}{c}\bullet \text { Amor y sangre } \\
\text { (novela de estos tiempos } \\
\text { de guerra) }\end{array}$ & $1-85$ & 96 \\
\hline 9 & $\begin{array}{c}\text { XII } / 1937] \\
n^{\circ} \text { extra. de } \\
\text { Navidad }\end{array}$ & Jorge Villarín & $\begin{array}{c}\text { - La enfermera de } \\
\text { Ondárroa }\end{array}$ & $5-90$ & 94 \\
\hline 10 & [I/1938] & Guy Wirta & Ninón & & \\
\hline 11 & $\begin{array}{l}\text { [II/1938] } \\
\text { hoja de } \\
\text { censura : }\end{array}$ & Juan Bautista Viza & $\begin{array}{c}\text {-Rosa-Roja y Flor de Lis } \\
\text { (novela de revolución y } \\
\text { de guerra) }\end{array}$ & $1-86$ & 96 \\
\hline
\end{tabular}

${ }^{80}$ Hemos sustituido las cifras romanas utilizadas en la colección por cifras árabes, más cómodas. Los números que no fueron localizados se indican entre corchetes ([...]).

${ }^{81}$ El signo $\bullet$ se aplica a las novelas relacionadas con la Guerra Civil española. 


\begin{tabular}{|c|c|c|c|c|c|}
\hline & $\begin{array}{l}\text { entrada: } \\
\text { 1/XII/1937 }\end{array}$ & & & & \\
\hline 12 & [III/1938] & Magali & El jardín encantado & $1-86$ & 96 \\
\hline 13 & [IV/1938] & $\begin{array}{l}\text { Matilde [Mathilde] } \\
\text { Alanic }\end{array}$ & Siempre vence el corazón & $1-91$ & 96 \\
\hline 14 & {$[\mathrm{~V} / 1938]$} & Florencia O’Noll & El pequeño Paganini & $1-86$ & 96 \\
\hline 15 & $\begin{array}{c}{[\mathrm{VI} / 1938]} \\
* 20 / \mathrm{III} / 1938\end{array}$ & $\begin{array}{c}\text { Concepción Castella de } \\
\text { Zavala }\end{array}$ & - Hágase tu voluntad & $5-74$ & 80 \\
\hline 16 & $\begin{array}{c}\text { [VII/1938] } \\
* \text { San } \\
\text { Sebastián, II } \\
\text { Año Triunfal, } \\
\text { Enero 1938 }\end{array}$ & $\begin{array}{c}\text { Ramón Solsona y } \\
\text { Cardona }\end{array}$ & $\begin{array}{c}\text {-Por mi Patria y por mi } \\
\text { dama* }\end{array}$ & $1-96$ & 96 \\
\hline 17 & [VIII/1938] & Cristina Busquets & El collar de Rosalinda & $1-91$ & 96 \\
\hline 18 & [IX/1938] & K. Tinan & Kitty & & \\
\hline 19 & {$[\mathrm{X} / 1938]$} & Jeanne de Co[u]lomb & El misterio de Corfú & & \\
\hline 20 & {$[\mathrm{XI} / 1938]$} & [Jacques] Des Gachons & Cuento de brujas & & 80 \\
\hline 21 & [XII/1938] & José María Pemán & $\begin{array}{c}\text { Fierabrás } \\
\text { Estampas románticas } \\
\text { •Por eso... }\end{array}$ & $\begin{array}{c}5-36 \\
37-60 \\
61-74\end{array}$ & 80 \\
\hline 22 & [I/1939] & Magali & $\begin{array}{l}\text { Corazones altivos } \\
\text { (edición refundida) }\end{array}$ & $1-100$ & 100 \\
\hline 23 & [II/1939] & G. [Gaston] de Wailly & $\begin{array}{c}\text { Con las mismas armas } \\
\text { (edición refundida de la } \\
\text { doble farsa) }\end{array}$ & $1-95$ & 96 \\
\hline 24 & [III/1939] & $\begin{array}{l}\text { C. }[\text { Claire] de } \\
\text { Chandeneux }\end{array}$ & El enigma del torreón & & \\
\hline $25^{82}$ & [IX/1939] & Cristina Busquets & $\begin{array}{c}\text { El juramento de } \\
\text { Fernando }\end{array}$ & & \\
\hline 26 & {$[\mathrm{X} / 1939]$} & Henry Ardel & Ilusión y realidad & & \\
\hline 27 & [X/1939] & G. [Gaston] de Wailly & Una herencia y un amor & & \\
\hline $\begin{array}{c}28 \\
{[1,50 \text { ptas. }]}\end{array}$ & [XI/1939] & Delly & Hija de héroes & & \\
\hline 29 & [XI/1939] & Barón de Casaportierra & El cantar de la muerta & & \\
\hline 30 & [XII/1939] & Henry Ardel & Cómo quiero ser amada & & \\
\hline 31 & [XII/1939] & María Sepúlveda & Dos vidas & & \\
\hline 32 & {$[\mathrm{I} / 1940]$} & Delly & La casa de los ruiseñores & & \\
\hline 33 & [I/1940] & $\begin{array}{c}\text { Concepción Castella de } \\
\text { Zavala } \\
\end{array}$ & La hija de la Alhambra & $1-91$ & 96 \\
\hline 34 & [II/1940] & Gustavo del Barco & El mejor Médico: Amor & & \\
\hline 35 & [II/1940] & Mayor V. Horse & El robo del protocolo & & \\
\hline 36 & [III/1940] & M. Aigueperse & $\begin{array}{c}\text { La muchacha que debió } \\
\text { ser chico }\end{array}$ & & \\
\hline 37 & [III/1940] & María Sepúlveda & Revelación & $1-91$ & 96 \\
\hline 38 & {$[\mathrm{IV} / 1940]$} & Delly & $\begin{array}{l}\text { La paloma de Rudsay- } \\
\text { Manor }\end{array}$ & & \\
\hline 39 & [IV/1940] & Manuel Segura & La torre de los Lujanes & & \\
\hline 40 & [V/1940] & Mary Floran & Sin fortuna y sin amor & & \\
\hline
\end{tabular}

${ }^{82}$ El traslado a Barcelona se realizó sin duda al terminar la contienda. Fue seguramente entonces cuando se inició su ritmo bimensual. 
Tropelías. Revista de Teoría de la Literatura y Literatura Comparada, 23 (2015)

La Biblioteca Rocío (1937-1939) o las virtudes de la novela rosa durante la Guerra Civil...

\begin{tabular}{|c|c|c|c|c|c|}
\hline 41 & [V/1940] & Barón de Casaportierra & La máscara duende & $\begin{array}{c}\text { coll. } \\
\text { Margarita }\end{array}$ & \\
\hline $\begin{array}{c}42 \\
2,50 \text { ptas. }\end{array}$ & [VI/1940] & G. de Wailly & $\begin{array}{l}\text { El amor bajo los hielos } \\
\text { (edición refundida de El } \\
\text { juramento de Lucía } \\
\text { publicada en la } \\
\text { Colección Princesa) }\end{array}$ & $1-93$ & 96 \\
\hline 43 & [VI/1940] & Delly & Anita & & \\
\hline 44 & {$[\mathrm{VII} / 1940]$} & $\begin{array}{c}\text { Concepción Castella de } \\
\text { Zavala }\end{array}$ & -La Rosa del Maestrazgo & $1-78$ & 80 \\
\hline 45 & {$[\mathrm{VII} / 1940]$} & Pedro Alciette & $\begin{array}{l}\text { Amor, Amistad y } \\
\text { Sacrificio }\end{array}$ & & \\
\hline 46 & [VIII/1940] & Gustavo del Barco & Tú y la Giralda & & \\
\hline 47 & [VIII/1940] & M.arguerite Levray & Legado de amor & & \\
\hline 48 & [IIX/1940] & Mario Rocormo & Cascabel de España & & \\
\hline 49 & {$[\mathrm{IIX} / 1940]$} & Delly & El Rey de los Andes & & \\
\hline 50 & [IX/1940] & [?] & $?$ & & \\
\hline 51 & [IX/1940] & Gustavo del Barco & Diga & & \\
\hline 52 & {$[\mathrm{X} / 1940]$} & Delly & Sombras & & \\
\hline 53 & {$[\mathrm{X} / 1940]$} & María Sepúlveda & Un caso singular & & \\
\hline 54 & [XI/1940] & Martín Tena sánchez & Por los caminos del Amor & & 80 \\
\hline 55 & [XI/1940] & Delly & Hipócrita & & \\
\hline 56 & {$[\mathrm{XII} / 1940]$} & Rosa de Nancy & Milagro de amor & & \\
\hline 57 & {$[\mathrm{XII} / 1940]$} & Gustavo del Barco & Angel de ojos verdes & & \\
\hline 58 & [I/1941] & Rafael J. Salvia & Horas perdidas & & \\
\hline 59 & [I/1941] & Concha Espina & Cura de amor & 1 & \\
\hline 60 & [II/1941] & Marcel Idiers & Un rapto misterioso & & \\
\hline 61 & [II/1941] & Juan de la Brète & Hablan los viejos muros & 7 & 80 \\
\hline 62 & [III/1941] & Rafael López de Hoyos & Ojos claros & & \\
\hline 63 & [III/1941] & María Sepúlveda & Contra sí misma & & \\
\hline 64 & [IV/1941] & $\begin{array}{l}\text { Eduardo } \\
\text { Marquina } \\
\end{array}$ & Destino cruel & & \\
\hline 65 & [IV/1941] & G. del Barco & Aquella sonrisa & & \\
\hline 66 & {$[\mathrm{~V} / 1941]$} & Rosa de Nancy & La pasajera $n^{\circ} 14$ & & 80 \\
\hline 67 & [V/1941] & Marcel Idiers & El secreto de Crista & & \\
\hline 68 & [VI/1941] & $\begin{array}{c}\text { Concepción Castella de } \\
\text { Zavala }\end{array}$ & Santina & & \\
\hline 69 & [VI/1941] & Celia de Luengo & Entre peñas & & \\
\hline 70 & [VII/1941] & Marcel Idiers & Un corazón vencido & & \\
\hline 71 & [VII/1941] & Gustavo del Barco & La casa de las lágrimas & & \\
\hline 72 & [VIII/1941] & Rafael J. Salvia & Una millonaria ingenua & & \\
\hline 73 & [VIII/1941] & Concha Espina & El hombre y el mastín & & \\
\hline 74 & [IX/1941] & Gustavo del Barco & Sahra & & \\
\hline 75 & [IX/1941] & Concha Gracián & Romería triunfal & & \\
\hline 76 & {$[\mathrm{X} / 1941]$} & Curtis Yorke & Doris & & \\
\hline 77 & {$[\mathrm{X} / 1941]$} & $\mathrm{M}^{\mathrm{a}}$ Mercedes Ortoll & Destinos del Corazón & & 88 \\
\hline 78 & {$[\mathrm{X} / 1941]$} & Gustavo del Barco & El gran fracasado & & 80 \\
\hline 79 & {$[\mathrm{X} / 1941]$} & Marcel Idiers & Una prueba decisiva & & \\
\hline 80 & {$[\mathrm{X} / 1941]$} & Mercedes Flores & $\begin{array}{c}\text { Cuando interviene el } \\
\text { amor }\end{array}$ & & \\
\hline 81 & [XI/1941] & Jean de la Brète & Te creo & & \\
\hline 82 & {$[\mathrm{XI} / 1941]$} & María Sepúlveda & La gran lección & & \\
\hline
\end{tabular}


Didier Corderot

\begin{tabular}{|c|c|c|c|c|}
\hline 83 & {$[\mathrm{XII} / 1941]$} & Gustavo del Barco & El maestro rural & \\
\hline 84 & [XII/1941] & $\mathrm{M}^{\mathrm{a}}$ Teresa Pérez Mayo & Oro y Azul & \\
\hline 85 & [I/1942] & Alice Pujo & Rosa Perrín & \\
\hline 86 & [I/1942] & Concha Gracián & ¡Al fin! & \\
\hline 87 & [II/1942] & Gustavo del Barco & Ella y Él: Tú y Yo & 76 \\
\hline 88 & [II/1942] & Magali & Roberto & \\
\hline 89 & [III/1942] & Mary Mar & ¿Quién es él? & \\
\hline 90 & [III/1942] & Marcel Idiers & Cuando llama el corazón & 80 \\
\hline 91 & [IV/1942] & Gustavo del Barco & La cómica & 84 \\
\hline 92 & [IV/1942] & Rosa de Nancy & La novia del mundo & \\
\hline 93 & [V/1942] & Guy Wirta & El rey Jack & 84 \\
\hline 94 & $\begin{array}{c}\text { [V/1942] } \\
\text { Publicación } \\
\text { quincenal, } \\
\text { Sevilla, } \\
\text { Barcelona, } \\
\text { Ediciones } \\
\text { Betis, } \\
\text { impresor } \\
\text { Fidel } \\
\text { Rodríguez, } \\
2 \text { ptas., } \\
\end{array}$ & $\begin{array}{c}\text { Concepción Castella de } \\
\text { Zavala }\end{array}$ & Dogal de Oro & 80 \\
\hline 95 & [VI/1942] & Magali & Hechizo & \\
\hline 96 & [VI/1942] & Concha Gracián & Reflejos & 80 \\
\hline 97 & [VII/1942] & Gustavo del Barco & $\begin{array}{c}\text { El hombre que volvió a } \\
\text { nacer }\end{array}$ & 84 \\
\hline 98 & & Laura de Noves & Las amó a todas & \\
\hline 99 & & Rodolphe Bringer & El sobrino de América & 2 \\
\hline 100 & & Ilde Gir & ¡Pícaro amor! & 80 \\
\hline 101 & & Magali & La quimera de Anita & \\
\hline 102 & & María Sepúlveda & A pesar de todo & 80 \\
\hline 103 & & Gustavo del Barco & $\begin{array}{c}\text { Confidencias (Memorias } \\
\text { de la Princesa María } \\
\text { Fernanda) }\end{array}$ & 80 \\
\hline 104 & & Pedro Gourdon & Felipe y Alicia & \\
\hline 105 & & $\begin{array}{l}\text { Heliodoro Lillo } \\
\text { Lutteroth }\end{array}$ & Huerto cerrado & 80 \\
\hline \multicolumn{5}{|l|}{$[\ldots]$} \\
\hline 107 & & Magali & Frente al mar & \\
\hline 108 & & Gustavo del Barco & La vida es esto & 80 \\
\hline 109 & & Mary Mar & Invito a usted a mi yate & \\
\hline 110 & & Henry Ardel & Dulce melodía & \\
\hline 111 & & Rosa de Nancy & La muchacha del Oeste & \\
\hline 112 & & Gustavo del Barco & Una mancha de carmín & \\
\hline \multicolumn{5}{|l|}{$[\ldots]$} \\
\hline 114 & & Celia Luengo & Corazón de hombre & \\
\hline \multicolumn{5}{|l|}{$[\ldots]$} \\
\hline 116 & & María Albuquerque & La piedra de imán & \\
\hline 117 & & Laura de Noves & Al servicio del corazón & \\
\hline 118 & & Magali & El amor de un cineasta & \\
\hline 119 & & $\begin{array}{c}\text { Concecpción Castella } \\
\text { de Zavala }\end{array}$ & Rosas de fuego & \\
\hline
\end{tabular}


Tropelías. Revista de Teoría de la Literatura y Literatura Comparada, 23 (2015) 47

La Biblioteca Rocío (1937-1939) o las virtudes de la novela rosa durante la Guerra Civil...

\begin{tabular}{|c|c|c|c|c|}
\hline 120 & & Isabel Marco & Almas rebeldes & \\
\hline 121 & & Magali & Mansión sin sol & \\
\hline 122 & & Gustavo del Barco & La voz de Dios & \\
\hline 123 & & Jean Rosmer & El marido de Alyette & 80 \\
\hline 124 & & Mercedes Flores & Amor que revive & \\
\hline \multicolumn{5}{|l|}{$[\ldots]$} \\
\hline 127 & & Marc Antonnis & Un dulce sueño & 80 \\
\hline 128 & & Rosa de Nancy & El amor vendrá después & \\
\hline \multicolumn{5}{|l|}{$[\ldots]$} \\
\hline 131 & & Rodolfo Bringer & El talismán de oro & 80 \\
\hline 132 & & Celia de Luengo & La perla y su concha & 80 \\
\hline 133 & & María Sepúlveda & La sombra de un pasado & \\
\hline 134 & & Alba d'Oro & Grato enigma & \\
\hline 135 & & $\begin{array}{l}\text { Mario Aresu [seud. de } \\
\text { Asunción Usera Ruiz] }\end{array}$ & $\begin{array}{l}\text { El misterio de la torre del } \\
\text { sur }\end{array}$ & 80 \\
\hline 136 & & Laura de Noves & $\begin{array}{c}\text { Qunieres usted ser mi } \\
\text { marido }\end{array}$ & \\
\hline 137 & & Magali & $\begin{array}{l}\text { Cárcel luminosa: } \\
\text { Imprudencia }\end{array}$ & 84 \\
\hline 138 & & Marina de Castaleñas & Habrá poesía & \\
\hline 139 & & Mary Floran & Dicha inapreciada & 80 \\
\hline 140 & & Gustavo del Barco & Una periodista & 80 \\
\hline 141 & & Magali & La mensajera & 80 \\
\hline 142 & & María Adela Durango & Hasta el otoño en París & 80 \\
\hline 143 & +2 & María Sepúlveda & El otro amor & \\
\hline 144 & & C. A. Gonnet & Ojos felinos & \\
\hline \multicolumn{5}{|l|}{$[\ldots]$} \\
\hline 146 & $\bar{z}$ & Lise de Cere & El encuentro de Silvia & 88 \\
\hline 147 & & Ivonne Bourget & Amor interceptado & 80 \\
\hline 148 & & Magali & Castigo dichoso & \\
\hline 149 & & $\begin{array}{l}\text { Carmen Nonell } \\
\text { Masjuan }\end{array}$ & $\begin{array}{l}\text { Seis muchachas } \\
\text { estudiantes }\end{array}$ & 80 \\
\hline \multicolumn{5}{|l|}{$[\ldots]$} \\
\hline 151 & & María Adela Durango & La grupa soñante & \\
\hline 152 & & Alejandro Liaño & Capricho del destino & 72 \\
\hline 153 & & René Star & Rivales & 94 \\
\hline \multicolumn{5}{|l|}{$[\ldots]$} \\
\hline 155 & & René Renolt & La inesperada esposa & 94 \\
\hline 156 & & Marcel Idiers & Mi Taqui-Meca & 80 \\
\hline 157 & & A. de Valdemir & Incógnita & 88 \\
\hline \multicolumn{5}{|l|}{$[\ldots]$} \\
\hline 159 & & Rosa de Nancy & Elena & 80 \\
\hline 160 & [1944?] & Magali & El raptor & \\
\hline 161 & & Gustavo del Barco & El Príncipe Pablo & 78 \\
\hline 162 & & Jules Sandeau & Una herencia & 80 \\
\hline 163 & & Ivonne Bourget & El beso de Montparnasse & 80 \\
\hline 164 & & Susana March & La otra Isabel & \\
\hline 165 & & Luis G. Manegat & Cautiverio de almas & \\
\hline \multicolumn{5}{|l|}{$[\ldots]$} \\
\hline 167 & & Susana March & Cumbre soliaria & \\
\hline$[\ldots]$ & & & & \\
\hline
\end{tabular}


48 Tropelías. Revista de Teoría de la Literatura y Literatura Comparada, 23 (2015)

Didier Corderot

\begin{tabular}{|c|c|c|c|c|}
\hline 169 & & Madame de la Fayette & La Princesa de Cleves & 132 \\
\hline \multicolumn{5}{|l|}{$[\ldots]$} \\
\hline 171 & & Gustavo del Barco & La Ría Inaga & \\
\hline \multicolumn{5}{|l|}{$[\ldots]$} \\
\hline 176 & & Mary Rowe & Extasis fugaz & 86 \\
\hline \multicolumn{5}{|l|}{$[\ldots]$} \\
\hline 179 & & A. Flory & El capitán negro & \\
\hline 180 & [1945?] & Carlos Ilmen & Zinochka & 70 \\
\hline \multicolumn{5}{|l|}{$[\ldots]$} \\
\hline 182 & & $\begin{array}{c}\text { Charito Torres [Rosario } \\
\text { Torres Gallego] }\end{array}$ & Yél era él & 70 \\
\hline 183 & & Jules de Saint Félix & Las cenas en Thermidor & \\
\hline \multicolumn{5}{|l|}{$[\ldots]$} \\
\hline 187 & & Gustavo del Barco & Un manojo de cartas & \\
\hline \multicolumn{5}{|l|}{$[\ldots]$} \\
\hline 189 & & Rosa de Nancy & Ella y el mar & \\
\hline \multicolumn{5}{|l|}{$[\ldots]$} \\
\hline 192 & & Magali & Estaba escrito & \\
\hline \multicolumn{5}{|l|}{$[\ldots]$} \\
\hline 194 & & Colette Yvon & Un marido alquilado & \\
\hline 195 & & Rosa de Nancy & Su retrato en el mar & \\
\hline \multicolumn{5}{|l|}{$[\ldots]$} \\
\hline 197 & & Concepción Sierra & Susana yél & 64 \\
\hline 198 & $\pi$ & Laura de Noves & $\begin{array}{c}\text { Patricia Packersón } \\
\text { pierde el tren }\end{array}$ & \\
\hline
\end{tabular}

